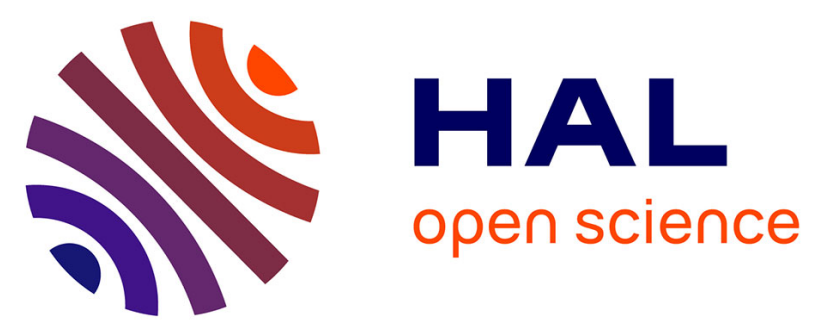

\title{
A Dual-band High Impedance Surface mounted with a spiral antenna for GNSS applications
}

Mélusine Pigeon, Christophe Morlaas, Hervé Aubert

\section{To cite this version:}

Mélusine Pigeon, Christophe Morlaas, Hervé Aubert. A Dual-band High Impedance Surface mounted with a spiral antenna for GNSS applications. APWC 2011 IEEE-APS Topical Conference on Antennas and Propagation in Wireless Communications, Sep 2011, Torino, Italy. pp 994 - 997, 10.1109/APWC.2011.6046821 . hal-01022277

\section{HAL Id: hal-01022277 \\ https://hal-enac.archives-ouvertes.fr/hal-01022277}

Submitted on 22 Sep 2014

HAL is a multi-disciplinary open access archive for the deposit and dissemination of scientific research documents, whether they are published or not. The documents may come from teaching and research institutions in France or abroad, or from public or private research centers.
L'archive ouverte pluridisciplinaire HAL, est destinée au dépôt et à la diffusion de documents scientifiques de niveau recherche, publiés ou non, émanant des établissements d'enseignement et de recherche français ou étrangers, des laboratoires publics ou privés. 


\section{A Dual-band High Impedance Surface mounted with a spiral antenna for GNSS Applications}

\author{
Mélusine Pigeon \\ PRES University of Toulouse \\ Toulouse, France \\ melusine.pigeon@recherche.enac.fr
}

\author{
Christophe Morlaas \\ LETA \\ ENAC \\ Toulouse, France
}

\author{
Hervé Aubert \\ LAAS \\ CNRS
}

Toulouse, France

\begin{abstract}
A low profile and dual-band High Impedance Surface to be used as a Artificial Magnetic Conductor for a GPS antenna is presented here. The two bands designed complete in simulation and in measure the GNSS characteristics.
\end{abstract}

\section{Keywords- HIS, Dual-Band, Spiral Antenna, measures}

\section{INTRODUCTION}

The design of low profile antennas has led to use High Impedance Surface (HIS) under the antenna. HIS have been widely investigated and it is known that they can be used as Artificial Magnetic Conductor to reduce the thickness of an electrical antenna above a metallic plate keeping an efficient radiation [1]. The main drawback of such structures is their relative narrow bandwidth. For GNSS applications, the total band (L1 to L5) is more than $40 \%$. To overcome this difficulty a dual-band structure is designed to insure the specifications of the GPS/GALILEO bands ( $2 \%$ at L5 (E5) band and 1,5\% at L1 (E1) band ). Moreover the HIS is designed to preserve the circular polarization of the antenna.

\section{II.THE DUAL-BAND HIS DESIGN}

The HIS proposed is composed of a collection of metallic patterns -named cells- periodically printed on a thin dielectric surface. This surface is placed in front of a metallic plate. The characteristics of the HIS in terms of operating frequency and bandwidth are determined first by the distance between this printed surface and the metallic plate (here $4 \mathrm{~mm}$ ) and second by the shape of cells.

The dual-band HIS is realised by pattern enclosing. First for L5 band, the pattern of the cell is a grid with localised capacitors (it forms the L5-cell as shown on Figure1). Second, for the L1 band, the pattern is a squared patch with localised capacitors (it forms the L1-cell as shown on Figure 2). In each hole of the L5-Cell (grid) a L1-cell is placed. The L5-cell capacitors are realised between two adjacent L5-cell. The L1cell capacitors are realised between a L1-cell and the adjacent edge of the L5-cell grid. For fixed cell dimensions, the resonant frequencies of each cells can be separately matched to the L1 and L5 frequency by mean of these capacitors. The L1-cell form a periodic structure inside the L5-cell.
Then the minimal size of the L5-cell is determined by the size of the active region of the antenna for the L1 frequency.

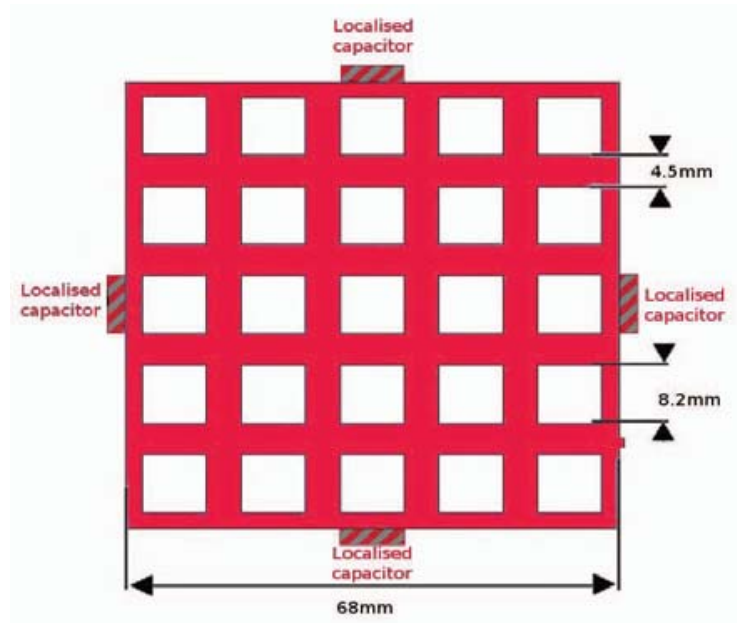

Figure 1. : The L5-cell with its localised capacitor

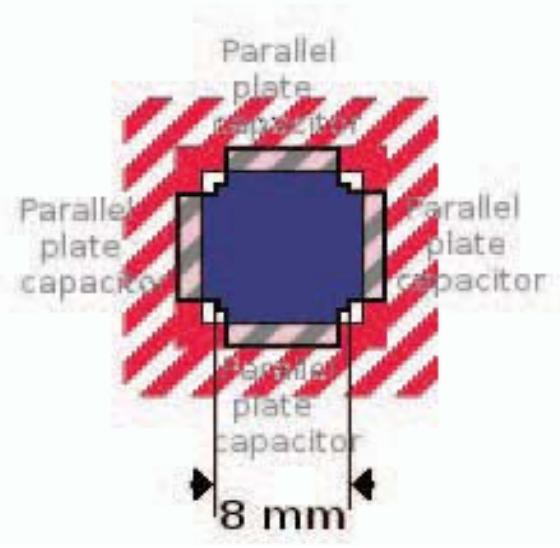

Figure 2: The L1-cell with its localised capacitors inside a hole of the L5-cell. 
For a half-wave dipole antenna, the active region is half of a wavelength. For a spiral antenna it is a disc of circumference of $\lambda$. One L5-cell enclosing 25 (5x5) L1-cells is called dualband cell, as shown in Figure 3. Finally, 9 (3x3) dual-band cells form the HIS.

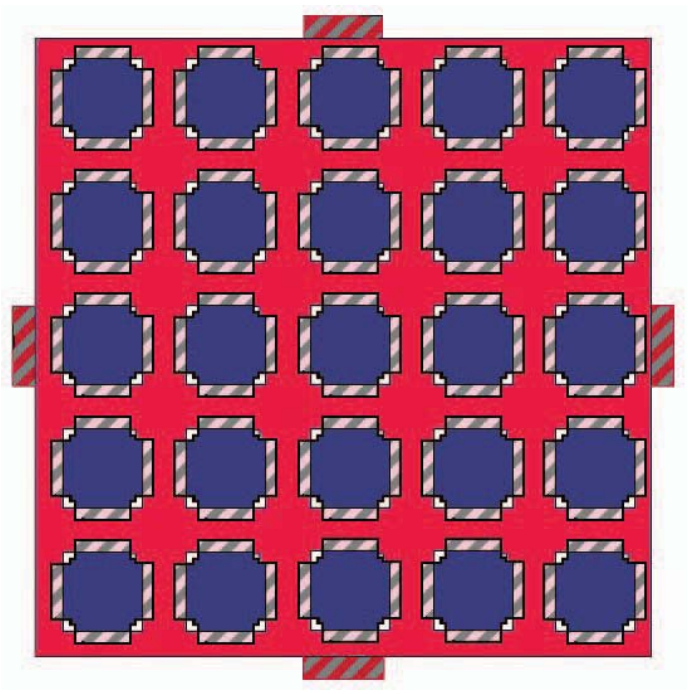

Figure 3: One dual-band cell..

\section{III.BLOCK-FLOQUET SIMULATIONS}

The dual-band cell is first designed and simulated using a commercial tool (HFSS). The cell is surrounded with periodic boundary conditions and a metallic plate is placed at $4 \mathrm{~mm}$ below the cell. This height is sufficient to insure the bandwidth specification. The cell is illuminated by the first Floquet mode under normal incidence. The reflection coefficient $\left(\mathrm{S}_{11}\right)$ of this mode is calculated in the plane of the cell. The bandwidth is measured by considering the phase of $\mathrm{S}_{11}\left(+/-90^{\circ}\right)$ [2] around the resonant frequency corresponding to $S_{11}=+1$.

The bandwidth of the L5 band is of $6 \%$ and the one of the L1 band is of $3 \%$ (conform with the GPS/GALILEO specifications). As shown in the Figure 4.

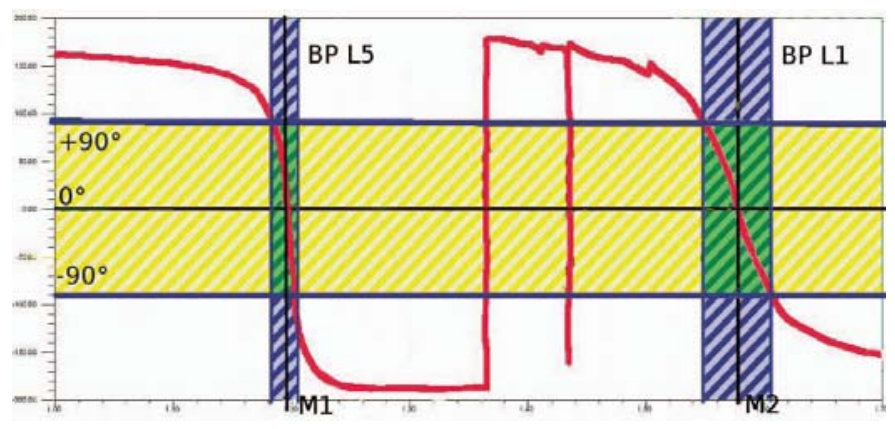

Figure 4: The S11 phase and the bandwidth associated to each focused frequencies.

\section{IV.CONCEPTION}

\section{A. The HIS}

For the realisation of the prototypes the localised capacitors are replaced by parallel plate capacitors. The L5-cell capacitors are created by alternating two L5-cells on one and the other side of a very thin dielectric ( $25 \mu \mathrm{m}$ of Kapton), as shown on Figure 5. The L1-cell capacitors are created between the patch and the grid. So the L1-cell are placed on one side of the dielectric and the L5-cell on the other side. And vice versa for the surrounding cells to insure the parallel plate capacitor between L5-cells. The entire structure is shown on Figure 6.

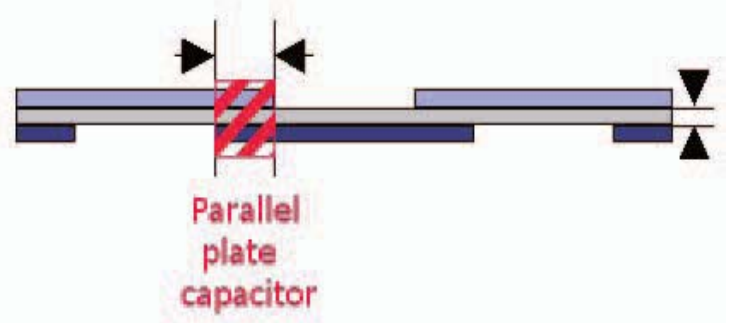

Figure 5: Parallel plate capacitor realised on each side of $25 \mu \mathrm{m}$ of Kapton.

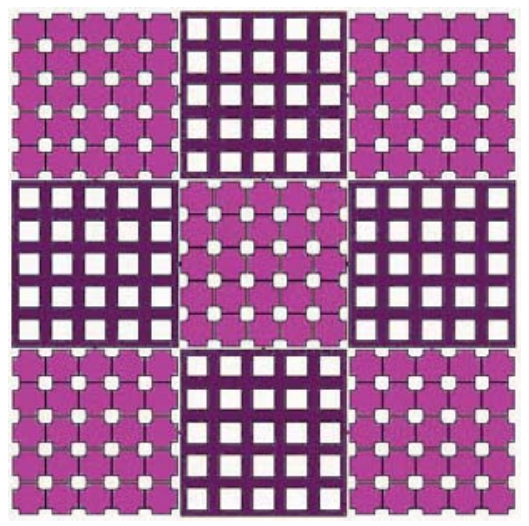

a)

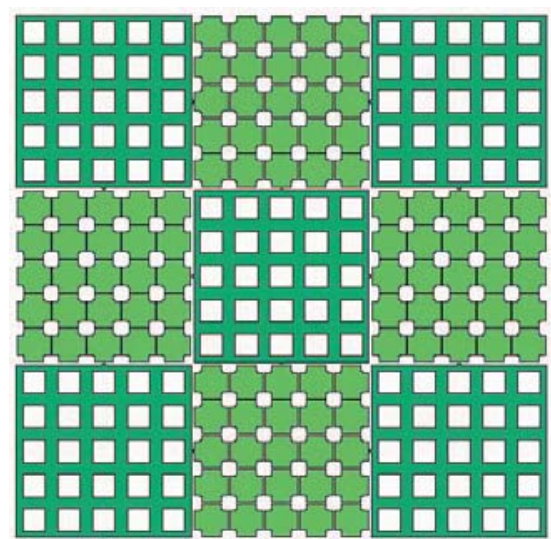

b)

Figure 6: The entire two layers structure with a) the top layer and b) the bottom layer 


\section{B. The antenna above the HIS}

To prevent a frequency msimatch between the measurements and the simulations, a spiral antenna is placed above the HIS. This spirale and its associated wideband balun are designed to have a bandwidth which covers all the GPS/GALILEO bands.

This spirale has a diameter of $12 \mathrm{~cm}$ and it is printed on a FR4-Epoxy dielectric of $0.8 \mathrm{~mm}$. The balun is based on [3-4].

\section{MEASUREMENTS}

The antenna mounted on the HIS is measured in an anechoïc chamber. For that the Friis equation between a known horn and our system is used.

\section{A. Measures protocole}

The HIS is expecting to act as an AMC. So the antenna placed above the HIS has to work as the antenna at $\lambda / 4$ above a metallic plane, for a distance between the antenna and the metallic below $\lambda / 4$ in the two designed bands.

The results are compared to the optimal case(distance antenna/metallic plane $=\lambda / 4$ without HIS). The simulated RHCP and LHCP gain and the axial ratio for this case is shown on Figure 7

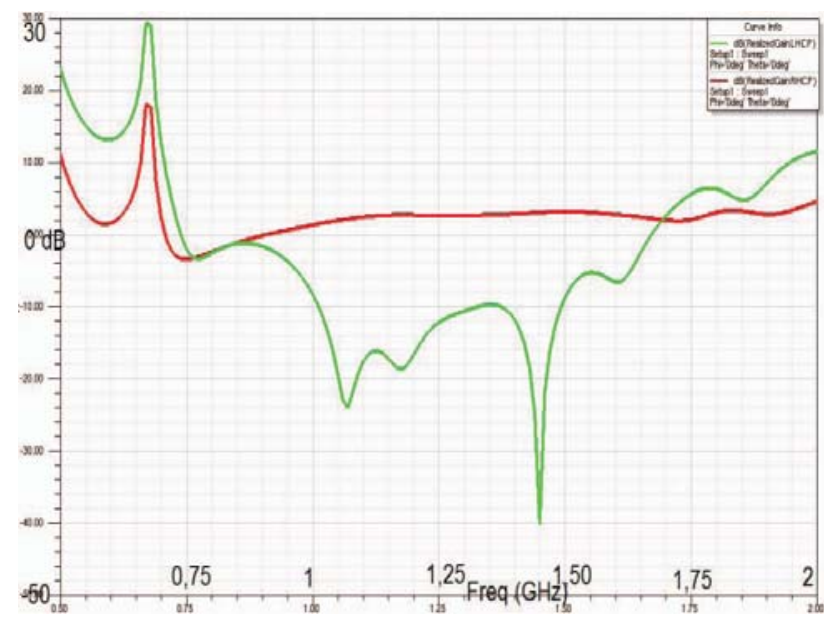

a)

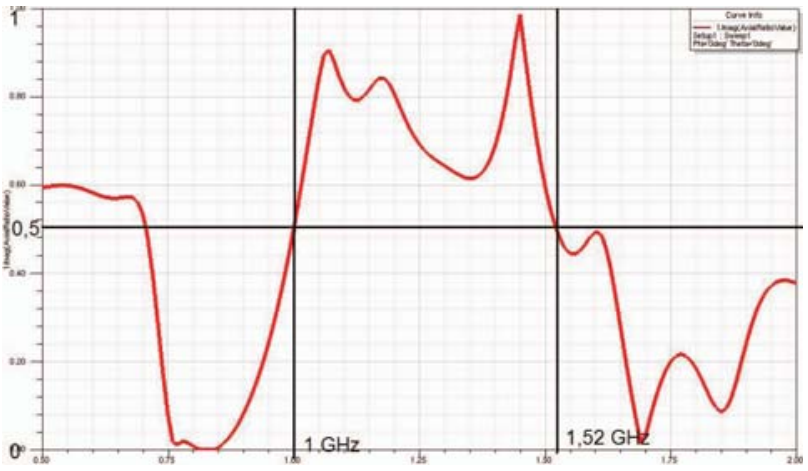

b)

Figure 7: a) Simulated RHCP and LHCP gain and b) the axial ratio of the spirale antenna at $\lambda / 4$ above a metallic plane
Two criteria are used to determine the working region of the system.

First the axial ratio of the system has to be above 0,5. Second, The RHCP gain of the system has to be the same than the on of the antenna at $\lambda / 4$ above a metallic plane.

Compare to the simulation in free space, the results are different mainly due to the limit size of the metallic plane.

In practice, the RHCP gain and the axial ratio are determined based on the measure of S21.

\section{B. Results}

\section{1) Reference}

As in simulation to have a reference point for comparison a measure with antenna at $\lambda / 4$ above a metallic plane is made.

The measured RHCP Gain are shown in Figure 8 and axial ratio are shown in Figure 9

For the GNSS bands the antenna works in limit of circular polarization, mainly for $1,39 \mathrm{GHz}$ and it is really borderline for the lower band (L5-E5). It is mainly due to the limits of the balun.

2) HIS

Now the designed HIS is placed under the antenna. In playing on the heights between the patterned and the metallic plane and between the antenna and the patterned plane, the two bands can be tuned. The measures shown correspond to a height of $7 \mathrm{~mm}$ between the metallic plane and the patterned plane and $24 \mathrm{~mm}$ between the antenna and the patterned plane.

The RHCP and LHCP Gain are shown on Figure 9 and the axial ratio for this configuration is shown on Figure 10.

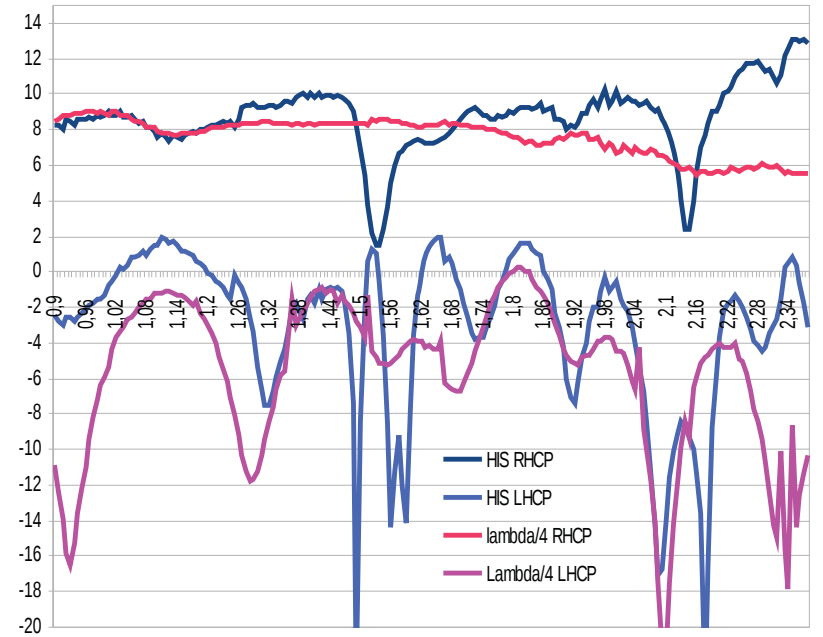

Figure 8: The measured RHCP and LHCP Gain ,in pink for the antenna at $\lambda / 4$ above the meatallic plane and in blue for the antenna above the HIS 


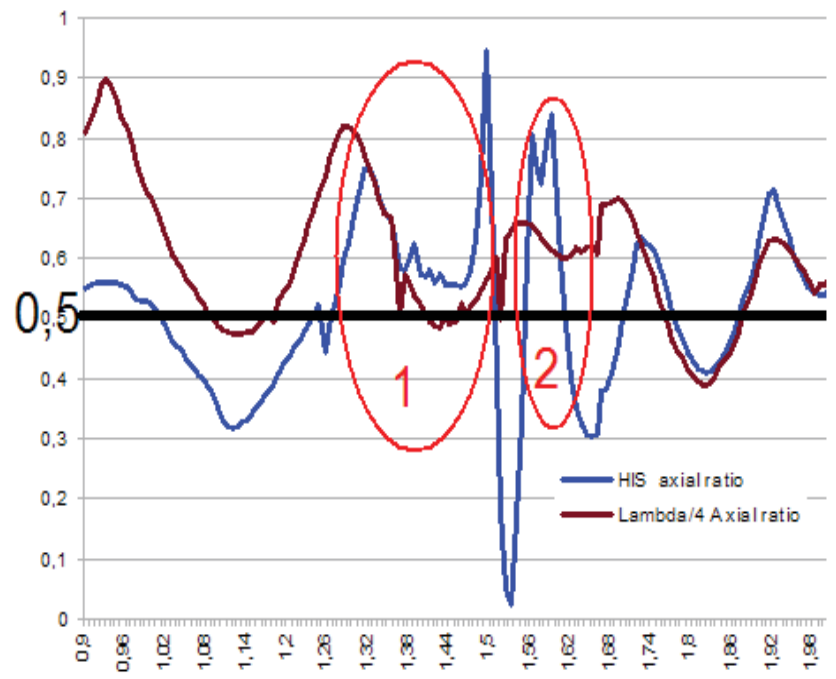

Figure 9: The Axial ratio ,in red for the antenna at $\lambda / 4$ above the meatallic plane and in blue for the antenna above the HIS

The two bands created by the HIS are circled on Figure 9.

As for the antenna at $\lambda / 4$ above the metallic plane the lower band (L5-E5) is difficult to reach due to the limit of the balun. Others measurements with a more appropriate will be made afterwards but they are not detailed in this article. The two bands created by the HIS are circled on Figure 10.

\section{VI.CONCLUSION}

The feasibility of a dual-band HIS covering the GPS/GALILEO specifications has been shown. The technique proposed in this paper can be extended to multiband devices. Some improvements can be considered to optimize the structure in particular on the balun and the thickness of the structure which is on air.

\section{ACKNOWLEDGMENTS}

Acknowledgments go to The Cibel company, Tonio Ida, Xavier Dollat and Michel Paonessa for their help in the realization of the prototypes and in measurements.

\section{REFERENCES}

[1] L.Akhoondzadeh-Asl, D.J.Kern, P.S. Hall, D.H. Werner, "Wideband Dipoles on Electromagnetic Bandgap Ground Planes", IEEE Transactions on Antennas and Propagation, Vol. 55 NO. 9., September 2007

[2] D. Sievenpiper, L. Zhang, R.F.J. Broas, N.G. Alexopolus, and E. Yablonovitch, "High-impedance electromagnetic surfaces with a forbidden frequency band », IEEE Trans. Microwave Theory Tech. Vol. 47, pp 2059-2074, Nov 1999

[3] Willmar K. Roberts, «A New Wide-Band Balun », Proceedings of the IRE, pp 1628-1631, December 1957.
[4] R. Bawer ans J. J. Wolfe « A Printed Circuit Balun for Use with Spiral Antennas » IRE transactions on microwave theory and techniques, pp 319-325, May1960. 